\title{
THE EFFECT OF EGG SIZE (WEIGHT) ON THE EGG SHELL THICKNESS, EGG YOLK AND HATCHABILITY IN KOEKOEK CHICKENS
}

\author{
Setsumi MOLAPO ${ }^{\star \otimes}$ and Mahlehla MOTSELISI \\ Department of Animal Science, National University of Lesotho, P.O. Roma 180, Lesotho \\ Emails: setsomimolapo@gmail.com; sm.molapo@nul.Is; (1) ORCiD: 0000-0002-4426-8901 \\ supporting Information
}

\begin{abstract}
The aim of this study was to determine the effect of egg size on egg shell, egg yolk, fertility rate and hatchability of Koekoek chickens. A Complete Randomized Design (CRD) was used with egg size being the treatment factor. The treatments were large $(>55 \mathrm{~g})$, medium $(45-54 \mathrm{~g})$ and small $(<44 \mathrm{~g})$ sized eggs. Eggs were collected from the nests and weighed using the digital scale and classified according to their respective weights before incubation. The egg yolk weight was measured with the digital scale. The shell thickness was measured using a Vanier caliper. The fertile and infertile eggs were identified. The fertility rate, hatching percentage and embryonic mortality were recorded. Data collected was subjected to statistical analysis by using one way analysis of variance (ANOVA). The medium sized eggs had higher fertility and hatchability percentage compared to large and small sized eggs. The mortality was higher in large and small sized eggs. Therefore, select eggs at the range of $\mathbf{4 5}$ to 55 grammes for incubation can be useful to increasing hatchability.
\end{abstract}

Keywords: Koekoek breed chickens, Egg size, Fertility rate, Hatchability, Embryo mortality.

\section{INTRODUCTION}

Chicken rearing is one of the most suitable activities to improve the livelihoods of the poor due to the advantages it has in terms of the small amount of capital required and the relative ease to set-up such a production system in the rural communities (Ja'afa-Furo and Gabdo, 2010; Stringer et al., 2020). In Lesotho, indigenous chickens remain predominant in the rural areas regardless of the introduction of exotic birds. Indigenous chickens have low output expressed in terms of low egg production, small egg size, slow growth rates and poor survival rate of chicks (Aganga et al., 2003).

Egg weight is one of the aspects affecting the quality of the egg and it is used among other factors as one of the external indicators for detecting quality of eggs (Jacob et al., 2000; Hegab and Hanafy, 2019). In the production cycle, the hen begin to lay small eggs and in a matter of few weeks she will go to medium and then large eggs as the birds age. Alasahan and Copur (2016) reported a positive correlation between egg weight, fertility and hatchability. Khurshid et al. (2003) discouraged the use of small and large sized eggs because of the indirect effects that prevent or reduce hatching.

The basic trend when hens grow is for eggs to become thin shelled. The hen is genetically capable of placing only a finite amount of calcium in the shell and she loses some of her ability to mobilize calcium from the bone (Gupta, 2008). Insufficient egg weight loss during incubation can reduce the gas exchange through the egg membrane promoting a decreased hatchability (Jones et al., 2010). Small and large eggs have high mortality percentage than medium egg, especially in local breeds (Abudabos et al., 2017).

This study was conducted to investigate the effect of egg size on the egg quality and hatchability of Koekoek chickens under Lesotho conditions.

\section{MATERIALS AND METHODS}

\section{Ethical approval}

The research and ethics committee in the Department of Animal Science of the National University of Lesotho approved this study based on international welfare standards for use of animals in conducting research. The study was conducted at the Department of Animal Science Experimental Farm of the National University of Lesotho located $35 \mathrm{~km}$ from Maseru, the capital of Lesotho. Koekoek chickens were collected using the egg trays from the flock comprised of cocks and hens, in the ratio of 1:10. Eggs were collected in clean nests three times a day to reduce cracking incidences. 
Five hundred and forty eggs were allocated into three egg size treatments in a Complete Randomized Design (CRD). The treatments were small $(<44 \mathrm{~g})$, medium $(45-54 \mathrm{~g})$ and large $(>55 \mathrm{~g})$. Each egg was taken as an experimental unit and there were three replicates per treatment and sixty (60) eggs per replicate. Ten eggs from each replicate were taken to determine the shell thickness and egg yolk. The shell thickness was measured using a Vanier caliper. The egg yolk was measured using a $0.01 \mathrm{~g}$ sensitivity level electronic scale. Eggs collected within eight days were taken to a sure hatch machine for incubation. Dirty, cracked and irregular shaped eggs were not selected for incubation. A $0.01 \mathrm{~g}$ sensitivity level electronic scale (RADWAG) was used to weigh the eggs. Eggs were fumigated with formalin potassium permanganate in a ratio 1:2 for 15 minutes before they were placed in an incubator. The temperature and humidity were set to $37.5^{\circ} \mathrm{C}$ and $82.5 \%$, respectively for incubation and $37.0^{\circ} \mathrm{C}$ and $85 \%$ for hatching. The eggs that were less than eight (8) days old were placed in an incubator. During the incubation period, the eggs were not turned for the first three days. From the fourth day to the eighteenth day, egg turning was done three times a day. The eggs were candled on 7 th day of incubation period in a dark room with the eggs held before a light. The infertile eggs were determined by the appearance of clear interior of the eggs and the fertile eggs were determined by presence of blood vessels. The numbers of infertile eggs were recorded. At the $18^{\text {th }}$ day, the eggs were removed from trays and placed into the hatching trays until hatching time. The incubator was not disturbed for the last three (3) days of incubation. The chicks were removed from the incubator on the morning of the $22^{\text {nd }}$ day. The fertility rate and hatching percentage of eggs were calculated as follows:

$$
\text { Fertility rate }=\frac{\text { Total number of fertile eggs }}{\text { Total number of incubated }} \times 100
$$

\section{Hatching percent $=$ Total number of eggs hatched $\times 100$ Total number of fertile eggs}

Eggs that failed to hatch were broken to determine the developmental stage of an embryo. The embryo mortality rate was measured by assessing at the developmental stage at which the un-hatched chick died using Hamburger and Hamilton (1992) method. An incubator was opted for instead of natural hatching due to the fact that it would be difficult to control the experiment since it would be difficult to get hens of the same age, size and behaviour. Above all, it would not be practical to assume that the hens would brood at the same time. Data was recorded in excel spreadsheet and averages were calculated. Data was tested for normal distribution. The analyses were done on transformed data. ANOVA was used to separate the effects of egg size on shell thickness, egg yolk, egg fertility, hatching percentage and embryo mortality. If significant, treatment effects were analysed and differences between treatments were tested by Duncan's new multiple-range test. The General Linear Models Procedure; SPSS (17.00) was used. Threshold for significance was $p<$ 0.05 .

\section{RESULTS AND DISCUSSION}

The results on shell thickness show that the small eggs had significantly thicker $(P<0.5)$ shells than medium and large eggs (Table 1). Increase in the egg size reduced the shell thickness by $8.3 \%$ and $25 \%$ comparatively to medium and small eggs respectively. Therefore, the chances of egg cracking and as well allowing more foreign bodies to penetrate (infection) an egg are higher and hence lower hatchability. This negative correlation between the shell thickness and egg size was also reported by Suki and Park (2001). The egg yolk weight from large eggs was significantly $(P<0.05)$ heavier than in medium and small sized eggs by $11.3 \%$ and $25.4 \%$ respectively (Table 1 ). Suki and Park (2001) also reported the proportion of egg yolk to be less in small eggs than in large ones.

\section{Table 1 - Effect of egg size on egg shell thickness and egg yolk of Koekoek chickens}

\begin{tabular}{l|cc|cc} 
Treatment (Egg size) & $\begin{array}{c}\text { Shell thickness } \\
(\mathbf{m m})\end{array}$ & S.E & Egg yolk (g) & S.E \\
\hline Large & $0.45^{\mathrm{a}}$ & 0.09 & $19.57^{\mathrm{a}}$ & 0.81 \\
Medium & $0.55^{\mathrm{b}}$ & 0.03 & $17.36^{\mathrm{b}}$ & 0.40 \\
Small & $0.60^{\mathrm{c}}$ & 0.15 & $14.60^{\mathrm{c}}$ & 0.24 \\
\hline abc Means within a row with no common superscript differ significantly p<0.05), S.E-standard error & \multicolumn{4}{l}{} \\
\hline
\end{tabular}

\section{Table 2 - Fertility rate and hatching percentage of different egg sizes}

\begin{tabular}{l|cc|cc} 
Treatment (Egg size) & $\begin{array}{c}\text { Fertility rate } \\
(\%)\end{array}$ & S.E & $\begin{array}{c}\text { Hatching percent } \\
(\%)\end{array}$ & S.E \\
\hline Large & $91.10^{\mathrm{a}}$ & 2.02 & $72.23^{\mathrm{a}}$ & 3.19 \\
Medium & $94.47^{\mathrm{a}}$ & 1.73 & $75.67^{\mathrm{a}}$ & 2.40 \\
Small & $88.60^{\mathrm{a}}$ & 1.93 & $71.00^{\mathrm{a}}$ & 3.86 \\
abc Means within a row with no common superscript differ significantly p<0.05), S.E-standard error & \multicolumn{4}{l}{} \\
\hline
\end{tabular}


Table 2 - Effect of egg size on embryonic mortality of Koekoek chickens

\begin{tabular}{lcc|cc} 
Treatment (Egg size) & Early mortality (\%) & S.E & Late mortality (\%) & S.E \\
\hline Large & 8.89 & 1.11 & 17.78 & 1.11 \\
Medium & 2.22 & 2.22 & 11.11 & 0.95 \\
Small & 7.78 & 2.94 & 12.22 & 2.01 \\
abc Means within a row with no common superscript differ significantly $p<0.05)$, S.E-standard error &
\end{tabular}

The results on egg fertility (Table 2 ) show that eggs at the range of medium size had insignificantly $(P<0.05)$ higher fertility rate compared to small and large sized eggs by $3.37 \%$ and $5.8 \%$ respectively. Seeker et al. (2004) also found higher fertility in medium size eggs. The hatching percentage was higher in medium sized eggs (75.7\%) compared to large (72.2\%) and small sized eggs (71\%) despite the differences being insignificant ( $p>0.05)$. This means that the medium size eggs have $3.4 \%$ and $4.7 \%$ better chances of hatchability than large and small eggs respectively. Asuquo and Okon (1993) reported an improved hatching percentage in eggs within the weight range of 45-56 grams than in small eggs. Medium size eggs yield $75 \%$ hatchability compared with $50-70 \%$ of small and large eggs (Hassan and Nordskog, 1971). Large eggs hatch poorly as compared to medium eggs (Khurshid et al., 2003). However, in a study that was conducted in New Hampshire and Red Rhode Island, De Witt and Schwakbach (2004) observed that large eggs had higher hatchability. Mbajiorgu (2011) also found that large-sized eggs of Venda chickens $(60-69 \mathrm{~g})$ had higher $(p<0.05)$ hatchability than medium (<50-59 g) and small-sized eggs (<49 g).

During the early stage of chick development, the embryonic mortality was lower in small eggs (2.2\%) than large and medium eggs with the early embryo mortality rates of $8.9 \%$ and $7.8 \%$ respectively (Table 3 ). During the late embryonic development the results show that the mortality rates of $17.8 \%, 11.1 \%$ and $12.2 \%$ for large, medium and small size eggs respectively. These results reveal an overall high embryonic mortality in large eggs than in other egg sizes even though the differences are not significant ( $p>0.05$ ). In support of these results, Monira et al. (2003) and Hasin et al. (2006) emphasized that the medium eggs normally have the lowest embryonic mortality with large eggs having the highest. Similarly, Jacob et al. (2000) also pointed out that medium sized eggs normally show the least mean score of embryo mortality at late stage of embryo development. Some researchers have also indicated that large eggs have higher incidences of embryo mortality at most developmental stages compared to medium and small eggs (Khushid et al., 2003; Monira et al., 2003; Hasin et al., 2006; Grochowska et al., 2019).

The thin egg shells in large eggs could be a possible reason for high mortality in large eggs. Eggs with thin shells are capable of losing more moisture during the during incubation because the thinner egg shell are more porous. This is in line with Islam (2001) who stated that water loss is one of the most important causes of embryonic death. Eggs with the poor shell quality, such as thin, porous or sandy shells should not be set for incubation (Parkhurst and Mountney, 1988). The relative humidity required for survival of an embryo should be $60-75 \%$, and the large eggs are said to be losing about $10-20 \%$ of their weight during storage and incubation (Parkhurst and Mountney, 1988). The higher embryonic death rate in small eggs can be attributed to more accumulation of calcium during shell formation hence a thicker shell and low moisture and exchange of gases. In support of these results, Jones et al. (2010) reported that insufficient egg weight loss during incubation can reduce the gas exchange through the egg membranes promoting increased embryonic deaths. Monira et al. (2003) also suggested that early deaths are the results of excess weight loss in eggs.

\section{CONCLUSION}

Egg size in Koekoek chickens had influence in the shell thickness, egg yolk, fertility rate, hatching percentage and embryo mortality. Thick and thin shells impact negatively on the hatchability of eggs. Incubating medium sized eggs improved the hatching percentage and reduced the embryonic death rates in Koekoek chickens. Therefore, farmers are advised to select eggs at the range of $\mathbf{4 5}$ to $\mathbf{5 5}$ grammes for incubation. This will ensure increased hatching percentage while other egg grades (small and large) can be used as table eggs.

\section{DECLARATIONS}

Corresponding Author

E-mail: sm.molapo@nul.Is ; setsomimolapo@gmail.com

Acknowledgements

The Department of Animal Science of the National University of Lesotho is acknowledged for funding this research.

Authors' Contribution

The authors contributed equally in this manuscript.

Conflict of interests

The authors have not declared any conflict of interests. 


\section{REFERENCES}

Abudabos AM, Aljumaah RS, Algawaan AS, Al-Sornokh H and Al-Atiyat RM (2017). Effects of Hen Age and Egg Weight Class on the Hatchability of Free Range Indigenous Chicken Eggs. Brazilian Journal of Poultry Science, 19(1): 33-40. Doi: https://dx.doi.org/10.1590/1806-9061-2016-0264

Aganga AA, Tshenyane SO and Molefhe L (2003). Influence of feed type on egg production of Tswana laying chicken. International Journal of Poultry Science, 2:256-258. http://citeseerx.ist.psu.edu/viewdoc/download?doi=10.1.1.494.3244\&rep=rep1\&type=pdf

Alasahan S and Copur AG (2016). Hatching Characteristics and Growth Performance of Eggs with Different Egg Shapes. Brazilian Journal of Poultry Science, 18 (1): 001-008. Doi: http://dx.doi.org/10.1590/1516-635x1801001-008

Asuquo BO and Okon B (1993). Effects of age in lay and egg size on fertility and hatchability of chicken eggs. Nigeria Journal of Animal Production, 20: 122-124. Doi: https://doi.org/10.1080/00128325.1993.11663183

De Witt F and Schwalbach LMJ (2004). The effect of egg weight on the hatchability and growth performance of New Hampshire and Rhode Island Red chicks. South African Journal of Animal Science, 34 (Suppl. 2), 62-64. Doi: https://www.sasas.co.za/journals/theeffect-of-egg-weight-on-the-hatchability-and-growth-performance-of-new-hampshire-and-rhode-island-red-chicks/

Grochowska E, Kinal A, Sobek Z, Siatkowski I, and Bednarczyk M (2019). Field study on the factors affecting egg weight loss, early embryonic mortality, hatchability, and chick mortality with the use of classification tree technique. Poultry Science, 98(9): 36263636. Doi: https://doi.org/10.3382/ps/pez180

Gupta L (2008). Factors influencing shell quality. Global Ag Media: The poultry site. https://www.thepoultrysite.com/articles/factorsinfluencing-shell-quality

Hamburger V and Hamilton HL (1992). A series of normal stages in the development of the chick embryo. Development Dynamics, 195: 231-272. Doi: https://doi.org/10.1002/aja.1001950404

Hasin BM, Ferdaus AJM, Islam MA, Uddin MJ and Islam MS (2006). Marigold and Orange Skin as Egg Yolk Color Promoting Agents. International Journal of Poultry Science, 5:979-987. Doi: https://doi.org/10.3923/ijps.2006.979.987

Hassan GM and Nordskog AW (1971). Effects of egg size heterozygosis on embryonic growth and hatching speed. Genetics, 67: $279-285$. PMID: 5569212

Hegab IM and Hanafy AM (2019). Effect of egg weight on external and internal qualities, physiological and hatching success of japanese quail eggs (Coturnix coturnix japonica). Brazilian Journal of Poultry Science, 21(3): eRBCA-2018-0777. Doi: https://doi.org/10.1590/1806-9061-2018-0777

Islam MA, Bulbul SM, Seeland G and Islam ABMM (2001). Egg quality of different chicken genotypes in summer and winter. Pakistan Journal of Biological Sciences, 4:1411-1414. Doi: https://scialert.net/abstract/?doi=pjbs.2001.1411.1414

Ja'afar-Furo MR and Gabdo BH (2010). Identifying major factors of poultry production as sustainable enterprise among farmers using improved methods in rural Nigeria. International Journal of Poultry Science, 9(5): 459-463. Doi: https://scialert.net/abstract/?doi=ijps.2010.459.463

Jacob, JP, Miles RD and Mather B (2000). Egg Quality. Institute of Food and Agricultural Sciences. University of Florida, Gainesville. http://edis.ifas.ufl.edu

Jones DR, Musgrove MT, Anderson KE and Thesmar HS (2010). Physical quality and composition of retail shell eggs. World Poultry Science Journal, 89 (3):582. Doi: https://doi.org/10.3382/ps.2009-00315

Khurshid A, Farooq M, Durrani FR, Sarbiland K and Chand N (2003). Predicting egg weight, shell weight, shell thickness and hatching chick weight of Japanese Quails using various egg Traits as regressors. International Journal of Poultry Science, 2 (2): 164-167. Doi: https://scialert.net/abstract/?doi=ijps.2003.164.167

Mbajiorgu CA (2011). Effect of hatching egg size on hatchability and chick hatch-weight of indigenous venda chickens. Indian Journal of Animal Research, 45(4), 300-304. https://www.indianjournals.com/ijor.aspx?target=ijor:ijar1\&volume=45\&issue=4\&article=010

Monira KN, Salahudding M and Miah G (2003). Effect of Breed and Holding Period on Egg Quality Characteristics of Chicken. International Journal of Poultry Science 2: 261-263. Doi: https://dx.doi.org/10.3923/ijps.2003.261.263

Parkhurst GR and Mountney GJ (1988). Poultry meat and egg production. Springer Science and Business Media. New York, Philadelphia. Doi: https://doi.org/10.1007/978-1-4757-0683-3

Stringer LC, Fraser EDG, Harris D, Lyon C, Pereira L, Ward CFM, and Simelton E. (2020). Adaptation and development pathways for different types of farmers. Environmental Science and Policy, 104: 174-189. Doi: https://doi.org/10.1016/j.envsci.2019.10.007

Suki YO and Park C (2001). Effect of Breed and Age of Hens on the Yolk to Albumin Ratio in Two Different Genetic Stocks. Poultry Science, 80:855-858. Doi: https://doi.org/10.1093/ps/80.7.855 